UDC 343.13

LBC 67.410.201

\title{
THE CRIMINAL PROCEDURE ASPECT OF DIFFERENTIATING CRIMINAL RESPONSIBILITY OF THE EXPERT AND SPECIALIST FOR PERJURY AND CONCLUSIONS
}

\author{
Alexander A. Tarasov \\ Bashkir State University, Ufa, Russian Federation \\ Aliya R. Sharipova \\ Bashkir State University, Ufa, Russian Federation
}

\begin{abstract}
Introduction: the establishment of criminal responsibility of the expert and specialist for perjury and knowingly false conclusions is a guarantee of the credibility of the data obtained from them. The differentiation of this responsibility and the determination of the nature of illegal actions of each of the named persons who have special knowledge are only possible through a clear demarcation of their criminal procedure rights and duties. The aim of this work is to identify the criminal procedure conditions for prosecuting the expert and specialist. In the study the authors used the methods of comparative law, historicism, structured system analysis and synthesis. Results: the analysis of the current Russian legislation, the criminal procedure legislation of Germany, which is the most similar to the Russian one in its conceptual framework and case law, shows the need to specify the criminal procedure status of the specialist in order not only to solve a lot of procedural problems of using his special knowledge, but also to ensure the strict differentiation of criminal responsibility of the specialist, expert and witness in case of their perjury during the investigation and in court. The differences in the procedural responsibilities of these persons create the features of the objective and subjective sides of illegal actions committed by them. Scope of application: the article may be useful in the field of legislation, law enforcement and science. Conclusions: the legally provided possibility to prosecute the experts and specialists for knowingly giving false opinions and testimony can be an effective means of ensuring the credibility of the evidence obtained with the use of their special knowledge, but only in case of maximum specification of the procedural status of the expert and specialist, which the current Russian law does not contain.
\end{abstract}

Key words: false testimony, false imprisonment, criminal responsibility, perjury, crimes against justice, special knowledge, calling for expert evidence, carrying out an expertise.

УДК 343.13

ББК 67.410 .201

\section{УГОЛОВНО-ПРОЦЕССУАЛЬНЫЙ АСПЕКТ ДИФФЕРЕНЦИАЦИИ УГОЛОВНОЙ ОТВЕТСТВЕННОСТИ ЭКСПЕРТА И СПЕЦИАЛИСТА ЗА ДАЧУ ЗАВЕДОМО ЛОЖНЫХ ПОКАЗАНИЙ И ЗАКЛЮЧЕНИЙ}

\author{
Александр Алексеевич Тарасов \\ Башкирский государственный университет, г. Уфа, Российская Федерация \\ Алия Рашитовна Шарипова \\ Башкирский государственный университет, г. Уфа, Российская Федерация
}

Введение: установление уголовной ответственности эксперта и специалиста за дачу заведомо ложных
показаний и заключений является гарантией достоверности получаемых от них сведений. Дифференциация 
этой ответственности и определение содержания противоправных действий каждого из названных обладателей специальных знаний возможны только благодаря четкому разграничению их уголовно-процессуальных прав и обязанностей. Цель работы состоит в выявлении уголовно-процессуальных условий привлечения эксперта и специалиста к уголовной ответственности. В исследовании использованы методы сравнительного правоведения, историзма, системно-структурного анализа и синтеза. Результаты: анализ действующего российского законодательства, уголовно-процессуального законодательства Германии, наиболее близкого к российскому по своим концептуальным основам, а также судебной практики убеждает в необходимости конкретизировать уголовно-процессуальный статус специалиста, с тем чтобы не только решить многие процессуальные проблемы использования его специальных знаний, но и обеспечить строгую дифференциацию уголовной ответственности специалиста, эксперта и свидетеля в случае сообщения ими заведомо ложных сведений на следствии и в суде. Различия в процессуальных обязанностях этих лиц порождают особенности объективной и субъективной стороны совершаемых ими противоправных действий. Область применения: статья может быть полезной для использования в области законотворчества, правоприменения и науки. Выводы: предусмотренная законом возможность привлечения экспертов и специалистов к уголовной ответственности за дачу заведомо ложных заключений и показаний может стать эффективным средством обеспечения достоверности доказательств, получаемых с использованием специальных знаний, но только в случае предельной конкретизации процессуального статуса эксперта и специалиста, которой в действующем российском законе нет.

Ключевые слова: заведомо ложные показания, заведомо ложное заключение, уголовная ответственность, лжесвидетельство, преступления против правосудия, специальные знания, назначение и производство экспертизы.

\section{Введение}

В статье 307 УК РФ (далее - УК) предусмотрена уголовная ответственность за недобросовестное выполнение уголовно-процессуальных обязанностей разных участников производства по уголовному делу, за сообщение органам расследования и суду заведомо ложных сведений [8]. Специфика действий, образующих объективную сторону этих преступлений, и их последствий, а также субъективного отношения виновного к происходящему и содеянному лично им в значительной степени определяется особенностями его процессуального статуса.

\section{Разграничение \\ уголовно-процессуального статуса эксперта и специалиста}

В наибольшей степени это касается проблемы разграничения уголовно-процессуального статуса двух внешне схожих процессуальных фигур - эксперта и специалиста, обладающих специальными знаниями и вовлеченных в уголовный процесс для выполнения разных по содержанию юридических и фактических действий. Эксперт - для производства экспертизы и для выполнения только тех действий, которые обусловлены назначением и производством судебной экспертизы. Специалист - для выполнения множества как процессуальных, так и внепроцессуальных действий, нормы о которых хаотично разбросаны чуть ли не по всему УПК РФ (далее - УПК): ст. 53, 58, 80, 144, 226.5 и др., кроме экспертизы. Устоявшиеся десятилетиями разграничительные критерии между экспертом и специалистом постепенно были ликвидированы законодателем. С июля 2003 г. специалист может давать заключения, с марта 2010 г. - проводить исследования (п. 3.1 ч. 2 ст. 74 , ч. 3 ст. 80 , п. 3 ч. 3 ст. 226.5, ч. 1 ст. 144 УПК), однако он по-прежнему не проводит экспертиз. Дача специалистом заключений в УПК не регламентирована, кроме довольно абстрактного упоминания в ч. 3 ст. 226.1. Допрашивается он на практике по правилам допроса свидетеля, однако без предупреждения его об уголовной ответственности за отказ от дачи показаний (ст. 308 УК), хотя по закону никакой специалист, кроме адвоката, в числе лиц, обладающих по российскому закону правом отказаться от дачи показаний, незначится.

\section{Исторический \\ и сравнительно-правовой аспекты проблемы}

Устав уголовного судопроизводства Российской империи 1864 г. обходился без разграничения статусов эксперта и специалис- 
та. Вскрытие трупа, например, осуществлялось в ходе «осмотра или освидетельствования» «мертвого тела» «чрез сведущих людей», обязанных не позднее трех суток составить «акт осмотра» или «свидетельство» (ст. 344 Устава), которые не заменяли протокола, составленного судебным следователем. Процессуальный статус «сведущих людей» в части возможности привлечения их к уголовной ответственности за сообщение органам расследования или суду заведомо ложных сведений традиционно ничем не отличался от статуса свидетеля. Такой же подход в равной мере характерен и для большинства современных национальных правовых систем как континентально-европейской [2, с. 122], так и англо-американской [1, c. 208-209] правовой семьи.

Действующий УПК ФРГ [9] с некоторыми оговорками распространяет на эксперта (Sachverständige) все положения о статусе свидетеля (§ 72). По германскому уголовно-процессуальному закону и свидетель (Zeuge), и эксперт по усмотрению суда могут быть приведены к присяге, и решение о том, приводить ли эксперта (§ 79) или свидетеля (§ 59) к присяге, принимается судом не до, а после дачи ими соответственно заключений или показаний. По правилам § 79 УПК Германии прежнее участие эксперта в качестве свидетеля по уголовному делу не является основанием для его отвода. В уголовном процессе России все совсем по-другому.

В $\S 85$ УПК ФРГ специально определяется статус свидетеля, обладающего специальными знаниями (Sachverständige Zeuge), которого в отечественной литературе предложено называть «сведущим свидетелем» [5, с. 113] по аналогии с обычным. В России лечащие врачи, например, дают показания об особенностях протекания и лечения заболеваний у их бывших или настоящих пациентов в качестве обычных свидетелей. И уголовной ответственности они подлежат точно на таких же основаниях если лгут следователю или суду (ст. 307 УК) или отказываются от дачи показаний (ст. 308 УК). Допрашиваемые российские врачи не пользуются свидетельским иммунитетом как носители профессиональной тайны, в отличие от германских врачей (§ 53 УПК ФРГ), что ставит их перед непростым нравственным выбором.

Название и диспозиция ст. 307 УК противоречат друг другу: в названии статьи фигурирует и показание, и заключение обоих сведущих лиц, а по диспозиции специалист несет уголовную ответственность только за заведомо ложные показания, что в литературе склонны считать лишь «технически неверно изложенной редакцией ст. 307 УК» [4, с. 33]. Полагаем, однако, что между заключением эксперта и заключением специалиста есть принципиальная разница, обусловленная тем, что первое может получаться только властвующим субъектом по результатам назначения экспертизы, а второе - любым представителем любой стороны. Выполнить объективную сторону преступления, предусмотренного ст. 307 УК, и в полной мере осознать уголовную противоправность совершаемых им действий специалист может только при официальном общении с тем субъектом, в производстве которого находится уголовное дело, то есть при даче им показаний.

Право эксперта отказаться от дачи заключения по мотивам собственной некомпетентности или недостаточности предоставленных в его распоряжение объектов прямо закреплено в п. 6 ст. 57 УПК. За специалистом закреплено общее право отказаться от участия в производстве по уголовному делу, если он не обладает соответствующими специальными знаниями. Однако если специалист уже участвовал в производстве, например, обыска или осмотра, сочтя, что для этого его знаний достаточно, то формально его можно обязать дать заключение специалиста по результатам этого следственного действия под угрозой наложения на него денежного взыскания (ч. 2 ст. 111 и ст. 117 УПК). В практике авторов подобный случай был [7, c. 65-67].

Формальную возможность привлечь эксперта и специалиста к уголовной ответственности за изложение в заключениях и показаниях заведомо ложных сведений принято считать гарантией достоверности доказательств, полученных с использованием специальных знаний. То же предполагается и в отношении свидетеля и переводчика. 


\section{Судебная практика}

Тенденции судебной практики таковы, что к ответственности может быть привлечен не любой «лжесвидетель», а только такой, который давал показания относительно «существенных обстоятельств дела», причем в ситуации, когда они повлияли или могли повлиять на вынесение законного и обоснованного решения суда. Последнее в реальности означает, что эти ложные показания могли сформировать у суда некое внутреннее убеждение, которое в свою очередь зависит не только от показаний одного «лжесвидетеля», но и от набора всех остальных доказательств по делу. В ситуации, когда суду, несмотря на ложные сведения, сообщенные свидетелем, удалось «разобраться» в деле, дача этих ложных показаний преступной не считается. Насколько описанный критерий неуловим и оценочен, можно судить хотя бы потому, что приводится он в необычайно редком в правоприменительной практике судебном акте - оправдательном приговоре [6]. Заметим, что общественная опасность лжесвидетельства определяется вовсе не его способностью влиять либо не влиять на установление юридически значимых обстоятельств дела, да еще и констатированной post factum. Лжесвидетельство на следствии и в суде опасно само по себе, независимо от последствий, состав преступления, предусмотренного ст. 307 УК, формальный.

Уголовные дела в отношении экспертов встречаются еще реже.

Обвинительным приговором Зареченского районного суда г. Тулы от 31 августа 2010 г. в отношении Шульгина и Кузнецова, оставленным без изменения кассационным определением Судебной коллегией по уголовным делам Тульского областного суда от 9 февраля 2011 г., в совершении, в том числе, преступления, предусмотренного ч. 1 ст. 307 УК, были осуждены государственный судебно-медицинский эксперт в качестве исполнителя и его непосредственный руководитель в качестве организатора. Последний, кроме того, был привлечен к ответственности за преступление, предусмотренное ч. 1 ст. 286 УК [3]. Полагаем, что осуждение этих лиц стало возможным во многом благодаря тому, что основным доказательством по делу явилась запись телефонного разговора, в котором руководитель дает указание подчиненному о даче определенного заключения еще до проведения судебномедицинского исследования. Запись была получена в ходе оперативно-розыскного мероприятия, а его проведение, надо полагать, было связано с какими-то «внепроцессуальными подозрениями» этих экспертов в том, что они могут давать заведомо ложные заключения.

Если в отношении свидетелей и экспертов, процессуальный статус которых довольно ясно определен в законе, практика привлечения к уголовной ответственности немногочисленна и избирательна, то в отношении специалистов ее вообще нет и едва ли исключительно потому, что они никогда не лгут следствию и суду. Что именно должен делать специалист, что сознавать и какой след об этом оставить в материалах уголовного дела - это при действующем уголовно-процессуальном законе является загадкой, на разгадывание которой хватит желания, времени и сил не у всякого правоприменителя.

\section{Выводы}

Неопределенность действующей нормативной регламентации уголовно-процессуального статуса эксперта и специалиста влечет за собой трудности в реализации уголовноправовых гарантий достоверности их заключений и показаний.

Конкретизация уголовно-процессуальных статусов носителей специальных знаний и порядка их привлечения к участию в деле позволила бы не только упорядочить использование специальных знаний в доказывании по уголовным делам, но и решить проблему дифференциации уголовной ответственности за сообщение следствию и суду заведомо ложных сведений.

\section{СПИСОК ЛИТЕРАТУРЫ}

1. Бернам, У. Правовая система США. Вып. 3 / У. Бернам. - М. : Новая юстиция, 2006. - 1216 с.

2. Головенков, П. Уголовно-процессуальный кодекс Федеративной Республики Германия Strafprozessordnung (StPO) / П. Головенков, Н. Спица. - М. : Проспект, 2013. $-311 \mathrm{c}$. 
3. Кассационное определение Судебной коллегии по уголовным делам Тульского областного суда от 9 февр. 2011 г. по делу № 22-186. - Доступ из справ.-правовой системы «КонсультантПлюс».

4. Кудрявцева, А. В. Процессуальный статус эксперта и специалиста: общее и особенное / А. В. Кудрявцева, Ю. А. Морозова // Дифференциация уголовного судопроизводства как гарантия обеспечения прав участников уголовного судопроизводства : сб. науч. ст. - Челябинск : Цицеро, 2015. - С. 30-49.

5. Орлов, Ю. К. Современные проблемы доказывания и использования специальных знаний в уголовном судопроизводстве / Ю. К. Орлов. - М. : Проспект, 2016. - 216 с.

6. Приговор Правобережного районного суда г. Липецка в отношении И.О. Кофановой в совершении преступления, предусмотренного ч. 1 ст. 307 УК. - Доступ из справ.-правовой системы «КонсультантПлюс».

7. Тарасов, А. А. Эксперт и специалист в уголовном процессе России / А. А. Тарасов. - М. : Проспект, 2017. - 126 с.

8. Тесленко, А. В. Уголовная ответственность за предоставление ложной информации, опасной для уголовного судопроизводства: сравнительно-правовой анализ законодательства Российской Федерации, стран континентальной Европы и Соединенных Штатов Америки : автореф. дис. ... канд. юрид. наук / Тесленко Антон Викторович. - Волгоград, 2017. - 23 с.

9. Strafprozessordnung der BRD. - Electronic text data. - Mode of access: http://www.gesetze-iminternet.de(stpo) (date of access: 31.05.2017). - Title from screen.

\section{REFERENCES}

1. Bernam U. Pravovaya sistema SShA. Vyp. 3 [The US Legal System. Iss. 3]. Moscow, 2006, pp. 208-209.

2. Golovenkov P., Spitsa N. Ugolovnoprotsessualnyy kodeks Federativnoy Respubliki Germaniya -Strafprozessordnung (StPO) [The Criminal Procedure Code of the Federal Republic of Germany - Strafprozessordnung (StPO)]. Moscow, Prospekt Publ., 2013. 311 p.

3. Kassatsionnoe opredelenie Sudebnoy kollegiey po ugolovnym delam Tulskogo oblastnogo suda ot 9 fevr. 2011 g. po delu № 22-186 [Cassation Determination by the Judicial Collegium for Criminal Cases of the Tula Regional Court of February 9, 2011 on Case no. 22-186]. Access from reference legal system "KonsultantPlyus".

4. Kudryavtseva A.V., Morozova Yu.A. Protsessualnyy status eksperta i spetsialista: obshchee i osobennoe [The Procedural Status of an Expert and a Specialist: General and Special Aspects]. Differentsiatsiya ugolovnogo sudoproizvodstva kak garantiya obespecheniya prav uchastnikov ugolovnogo sudoproizvodstva: sb. nauch. st. [Differentiation of Criminal Justice as a Guarantee of Ensuring the Rights of Participants in Criminal Proceedings: Collection of Scientific Articles]. Chelyabinsk, Tsitsero Publ., 2015, pp. 30-49.

5. Orlov Yu.K. Sovremennye problemy dokazyvaniya $i$ ispolzovaniya spetsialnykh znaniy v ugolovnom sudoproizvodstve [Modern Problems of Proof and Use of Special Knowledge in Criminal Proceedings]. Moscow, Prospekt Publ., 2016. 216 p.

6. Prigovor Pravoberezhnogo rayonnogo suda g. Lipetska votnoshenii I.O. Kofanovoy v sovershenii prestupleniya, predusmotrennogo ch. 1 st. 307 UK [The Verdict of the Right-Bank District Court of the City of Lipetsk in Respect of I.O. Kofanova in the Commission of Crime under Part 1 of Article 307 of the Criminal Code]. Access from reference legal system "KonsultantPlyus".

7. Tarasov A.A. Ekspert $i$ spetsialist $v$ ugolovnom protsesse Rossii [Expert and Specialist in the Criminal Procedure of Russia]. Moscow, Prospekt Publ., 2017. 126 p.

8. Teslenko A.V. Ugolovnaya otvetstvennost za predostavlenie lozhnoy informatsii, opasnoy dlya ugolovnogo sudoproizvodstva: sravnitelno-pravovoy analiz zakonodatelstva Rossiyskoy Federatsii, stran kontinentalnoy Evropy i Soedinennykh Shtatov Ameriki: avtoref. dis. ... kand. yurid. nauk [Criminal Liability for Providing False Information Dangerous for Criminal Proceedings: Comparative Legal Analysis of the Legislation of the Russian Federation, the Countries of Continental Europe and the USA]. Volgograd, 2017.23 p.

9. Strafprozessordnung der BRD. URL: http:// www.gesetze-im-internet.de(stpo) (accessed May 31, 2017). 


\section{Information about the Authors}

Alexander A. Tarasov, Doctor of Juridical Sciences, Professor, Head of the Department of Criminal Law and Procedure, Bashkir State University, Zaki Validi St., 32, 450076 Ufa, Russian Federation, aatar@mail.ru,rector@bsunet.ru.

Aliya R. Sharipova, Candidate of Juridical Sciences, Associate Professor, Department of Criminal Law and Procedure, Bashkir State University, Zaki Validi St., 32, 450076 Ufa, Russian Federation, nordwind23@mail.ru, rector@bsunet.ru.

\section{Информация об авторах}

Александр Алексеевич Тарасов, доктор юридических наук, профессор, заведующий кафедрой уголовного права и процесса, Башкирский государственный университет, ул. Заки Валиди, 32, 450076 г. Уфа, Российская Федерация, aatar@mail.ru, rector@bsunet.ru.

Алия Рашитовна Шарипова, кандидат юридических наук, доцент кафедры уголовного права и процесса, Башкирский государственный университет, ул. Заки Валиди, 32, 450076 г. Уфа, Российская Федерация, nord-wind23@mail.ru, rector@bsunet.ru. 